\title{
2 Measuring Orangutan nest structure using Unmanned Aerial Vehicle (UAV)
}

6 Salniza Akmar Kamaruszaman ${ }^{1 \uparrow}$, Nik Fadzly1ף,**, Aini Hasanah Abd Mutalib1థ, Aidy M.

7 Muslim $^{3 \&}$, Sri Suci Utami Atmoko ${ }^{4 \&}$, Mashhor Mansor $^{1 \&}$, Asyaf Mansor ${ }^{1,2 \&}$, Nadine Rupert ${ }^{1 \&}$,

8 Rahmad Zakaria ${ }^{1 \&}$, Zarul Hazrin Hashim ${ }^{1,2 \&}$, Amir Shah Ruddin Md Sah ${ }^{1 \&, ~ F a d h i r u l ~ F i t r i ~}$

$9 \quad$ Jamsari $^{5 \&}$, and Nur Munira Azman ${ }^{1 \&}$

10 'School of Biological Sciences, Universiti Sains Malaysia, 11800 Minden, Penang, MALAYSIA,

$11{ }^{2}$ Centre for Marine and Coastal Studies (CEMACS), Universiti Sains Malaysia, 11800 Minden, Penang, MALAYSIA.

$12{ }^{3}$ Institute of Oceanography and Environment (INOS), Universiti Malaysia Terengganu, 21030 Kuala Terengganu,

13 MALAYSIA.

$14 \quad{ }^{4}$ Fakultas Biologi, Universitas Nasional Jakarta, 12520,INDONESIA.

15 5FO Tech Sdn Bhd, Kuala Lumpur, 21-2, Jalan Wangsa Delima 10, Wangsa Maju, 53300 Wangsa Maju, Federal 16 Territory of Kuala Lumpur, MALAYSIA.

17

* Corresponding author

19

Email: nroselnik@outlook.com

『 These authors contributed equally to this work

21 \& These authors also contributed equally to this work 


\section{Abstract}

The nest is one of the crucial elements in orangutan daily activities. Previously, most of the nest structure studies were done manually by estimating measurement directly from visual observation. However, using the latest unmanned aerial vehicle (UAV) technology, we can reduce the workforce, time and energy while simultaneously ensuring the safety of the researcher conducting nest structure analysis. We recorded 49 pictures of orangutan nests at Sepilok Orangutan a strong, stable, and comfortable position at the top of the tree. Most orangutans chose and safe method for studying orangutan nest structure.

\section{Introduction}

Arboreal great apes especially orangutans need to master the nest building skill together with other

43 skills such as climbing, foraging and being able to identify their natural predators [1-4]. The nest

44 building is a skill inherited through observation on the mother's or other adults' nesting practices

$45[2,3,5,6]$. Nests served as a "bed" for resting and sleeping, hiding from danger or predator, as well as for a better thermoregulation $[4,5,7]$. 
47 Previously, most of the orangutans' nest studies were based on ecological aspects such as density estimation, distribution and population of orangutans in a habitat, nesting preferences and mechanisms and material to build a nest and its decaying rates [7-12]. Nest measurement and materials used are evaluating characteristics of the nest building skill of an individual and the

51 quality of the nest built $[6,13]$. However, researchers must conduct rigorous, time and energy

52 consuming techniques such as tree climbing to study the orangutan's nest structures. Even though

53 direct nests measurement by climbing techniques might provide a more accurate reading, a new 54 approach using Unmanned Aerial Vehicle (UAV) has been developed for nest survey and observation during this decade [7, 11, 13-15].

The application of UAV or drones technology was once limited to the military. However,

57 the usage of drones has spread widely and no longer exclusive to the military. Drones are used in 58 civilian use such as monitoring, transportation for goods delivery as well as site inspections [16,

59 17]. These drones have the capability to capture images through rapid data acquisition, which is an advantage for scientific research especially for animals conservations [8, 11, 16-19]. This study

61 aims to determine the variation of nest structure quantitatively via image analysis through utilization of drones.

\section{Materials and Method}

65

66 We obtained the permission to conduct the study from Sabah Biodiversity Centre (SaBC) with

67 the support of Sabah Wildlife Department (SWD) and Sabah Forestry Department (SFD). The 
within Kabili-Sepilok Forest Reserved with an area of 4294 hectares with more than 200

71 Orangutans (Fig 1).

72

73

74

75

76

77

78

79

80

81

82

83

84

85

86

87

Fig 1 The area of study; Sepilok Orangutan Rehabilitation Centre (Map by Aini Hasanah Abd Mutalib).

We tested a new experimental design by adapting to the nest description outlined by Samson and Hunt (6). We utilized the use of Unmanned Aerial Vehicle (UAV) to capture the orangutan nests images $[11,20]$. We used the DJI Phantom 3 Professional fitted with a 12-megapixel camera (f/2.8 lens $94^{0}$ field view). Image capture process was done without the presence of the orangutans during daytime for safety purposes (for the researchers and the orangutan). Our skilled licensed drone pilots managed to fly the drone as close as within 1 to 3 meters of the nest. The side and top view of the nest were recorded at a screen resolution of $72 \mathrm{dpi}$ (dot per inch) which equals to $300 \mathrm{dpi}$ in print resolution. The digital scale measurement of the nests' structure was estimated by using leaf samples of the tree where the nests were recorded. We used a slingshot to obtain the leaf samples from the nearest branch of the nest. The leaf samples were measured by using a ruler to obtain the length. Ten samples of the leaves were measured and we used the average value. In the ImageJ software, we used the measured length as the digital scale for the overall image analysis. ImageJ software was used to measure the nest length, width, and depth. The digital measurement of the nest was illustrated in Fig 2.

Fig 2 The mechanism of nest measurement using the ImageJ analysis was modified from van Casteren et al.,[7]. 1. Leaf sample (red boxes) was measured and set as digital scale (cm). 2.The length of the nest was measured, the depth of the nest was taken from the centre of the nest. 3. The nest width was measured perpendicular to the length. 

and tree species) were also recorded through direct observation. Nest class and position were

96 classified based on Utami Atmoko and Arif Rifqi (4) and Prasetyo, Utami (1). The nest canopy

97 cover was classified directly through observation in the field. The nest was categorized as closed

98 nest if there was the presence of tree canopy, vegetation, or any obstacle above the nest. A nest was considered as an open nest with the absence of any obstacles that prevent direct sunlight to the nest. The tree and nest height was either measured by using a clinometer (Suunto PM-5, PM$5 / 1520$ ) or estimated through observation. The tree species were identified by the available tree id tags and later reconfirmed by the SFD's staff. The data were analyzed by using statistical software JMP 10. The variables that were not normally distributed were transformed using log to meet the

105 proceeded to use non-parametric analyses.

\section{Results}

We recorded a total of 49 nests. Fig 3a shows most of the nest were built at tree branch or position class. 
115 The average nest length, width and depth recorded were $87.323 \pm 29.472 \mathrm{~cm}, 59.889 \pm 18.313 \mathrm{~cm}$

116

117

118

119

120

121

122

123

124

125

126

127

128

129

130

131

132

133

134

135

136

137

and $36.666 \pm 16.009 \mathrm{~cm}$, respectively. The average height of the tree, and the height of nest were

$16.166 \pm 7.686 \mathrm{~m}$, and $12.176 \pm 6.866 \mathrm{~m}$, respectively. $65.63 \%$ of the nests were open nest and

$34.63 \%$ of the nests were closed nest (Fig 4).

Fig 4 The pie chart shows the percentage nests built according to nest cover. Inset picture 1 and 2 show an open nest, inset picture 3 and 4 show a closed nest, from the top and side view.

There was no significant difference for nest position according to nest length (Kruskall-Wallis, $\chi^{2}$ $=2.138, \mathrm{df}=2, \mathrm{P}=0.343)$ and depth (Kruskall-Wallis, $\left.\chi^{2}=2.108, \mathrm{df}=2, \mathrm{P}=0.349\right)$. There was also no significant difference for the nest width based on the nest position (ANOVA, F $(2,77)=$ $1.839, \mathrm{P}=0.166)$. There was no significant difference for the nest class based on the nest length (Kruskall-Wallis, $\chi^{2}=4.304, \mathrm{df}=3, \mathrm{P}=0.231$ ).

There is a significant difference of nest depth based on the nest class (Kruskall-Wallis, $\chi^{2}=13.408$, $\mathrm{df}=2, \mathrm{P}=0.001)($ Fig 5). The depth of nest decreased with the nest class. Class 3 nest recorded the thinnest depth $(34.560 \pm 3.613 \mathrm{~cm})$ compared to nest from class $1(52.200 \pm 2.032 \mathrm{~cm}$ and class $2(57.000 \pm 2.430 \mathrm{~cm})$. There was no significant difference for nest class according to the nest width $(\mathrm{F}(3,77)=2.187, \mathrm{P}=0.097$. Tree height and nest height showed a strong positive and significant correlation $\left(\mathrm{r}_{\mathrm{s}}=0.7867, \mathrm{p}=0.0001\right)($ Fig 6).

Fig 5 : The nest depth based on the nest class distribution.

Fig 6: The correlation between a) height $(\log )$ of tree and height of nest

From the 49 nests recorded, 46.94\% (23 nests) were found on Eusideroxylon zwageri, 20.41\% (10 nests) on Nephelium rambutan-ake, 8.16\% (4 nests) on Litsea sp. and Syzygium rejangense, 4.08\% 
Fig 7: The frequency of tree species used for nesting by orangutan.

\section{Discussion}

The aim of this study was to determine the variation of nest structure quantitatively using advance

147 this study, the average length of nest was $87.32 \mathrm{~cm}$, which is within the range of the previous safety purposes. However, through observation we noted that juveniles and adults of both sex male individual tend to avoid crowd areas, therefore their nest might be secluded.

157 Orangutans might have avoided small trees as they preferred strong and sturdy branches to support preferred sturdy, strong and comfortable spot to build nest [1, 5-7]. 
Our results showed no significant differences between the nest sizes cumulatively. However, several studies have shown that nests size increases with the age group. This is related to the body size where adult flange male with large body size built larger nest compare to the juvenile with a small body $[7,13]$. In our study site, since we did not detect any adult flanged male nesting and most of the nests that we sampled were frequented by orangutans within a similar age group and body sizes. There is a possibility that a larger sample size could provide more information in the future.

The significant correlation between tree height and nest height supports the hypothesis which orangutans were more likely to build the nest at the very top of the tree. The decaying process might also have contributed to the significant difference between nest class and nest depth [10]. Class 3 is considered as the second last stage of nest decay. Orangutans usually repairs certain nest spots that are their favorite, which is why nest class 1 and 2 is frequently used. However, the decay rate or factors affecting the decay process and decay process related to nest class quality were not recorded in this study. There is also the possibility that the depth of the nest was influenced by the orangutan body weight. Orangutan would position themselves in the middle of the nest and their body weight would depress the whole nest. Unfortunately, since we did not specifically track individual orangutans to a specific nest, we could not confirm this effect. There was also no assessment related to the animal physical measurement such as weight and body size as we were not allowed to physically touch the orangutans.

Orangutan most likely avoided building nest on fruit trees as precautions steps from other individuals especially flange males or other frugivorous animals. However, with limited availability of fruit, there were cases where an individual would select the non-fruiting tree to build their nest [5, 21, 22]. Orangutans do have individual preferences in where to rest and sleep [4, 5]. 
183 Orangutans shows intelligence in nest building by choosing the best materials from hard and 184 durable tree species such as E. zwageri tree (commonly known as a Belian tree). Compared to 185 other tree species, the Belian tree would provide the orangutans a sturdy and strong nest to support their weight. This valuable timber is widely used by human to produce furniture, medicinal

187 purposes as well as in traditional rituals [23-26]. The frequent usage of this tree species also 188 indicates that orangutans chose their nesting site based on strong and sturdy tree more for their 189 comfort [27].

190 In natural settings, orangutans are solitary and have the tendency to avoid crowd and predators 191 including human $[4,28,29]$. In this study, we noticed that most of the orangutans have become 192 habituated with the human presence since most of the nests recorded were located near the feeding 193 platforms and boardwalk; a place where the visitors could access and observe the orangutan's 194 activities. We also suspected that this phenomenon was also due to food availability since the food 195 will be given to them every 10 a.m. and 3 p.m. regardless to the presence of visitors.

196 However, we must highlight the fact that the orangutans in Sepilok were in a rehabilitation 197 program which indirectly means that they were already familiar with human presence since they 198 have been exposed to human care. To release them into the wild, the juvenile orangutans were 199 released in the rehabilitation area within the 4,294-hectare forest. This was the next step in 200 preparing the orangutans to be released in the wild. The orangutan need to forage, build their own 201 nest, and subsequently making them less dependent on human care. Nest building skills is a very 202 crucial and important skill for orangutan to survive in the wild. Therefore, research on the nest 203 structure of orangutan is a very important. We propose that our method would be used as a standard 204 for future nest studies. 
205

206

207

208

209

210

211

212

213

214

215

216

217

218

219

220

221

222

223

224

225

226

227

228

229

230

231

232

233

234

235

236

237

238

\section{Acknowledgement}

We thank Universiti Sains Malaysia (USM) for providing the Research University grant. We also want to thank Sabah Biodiversity Centre (SABC) for approval of research permit. Thank you also to Sepilok Orangutan Rehabilitation Centre (SORC); Mr. Sailun, Mrs Sylvia and SORC staffs for assisting us during the sampling period. We acknowledge the Department of Aviation Malaysia (DCA) for the drone flight permission. A special thank you to Muhamad Armi Majid and Muhammad Shadzmir Kamalrulzaman from OFO Tech Snd. Bhd. for technical and drone piloting. Finally, our gratitude to Nagao Natural Environment Foundation, Orangutan Foundation International for the additional funding.

\section{References}

1. Prasetyo D, Utami SS, Suprijatna J. Nest stuctures in Bornean Orangutan. Jurnal Biologi Indonesia. 2012;8(2).

2. Russon AE, Handayani DP, Kuncoro $P$, Ferisa A. Orangutan leaf-carrying for nest-building: Toward unraveling cultural processes. Animal cognition. 2007;10(2):189-202.

3. Russon AE. Orangutan rehabilitation and reintroduction. Orangutans: Geographic variation in behavioral ecology and conservation. 2009:327-50.

4. Utami Atmoko S, Arif Rifqi M. Buku panduan survei sarang orangutan: Forum Orangutan Indonesia \& Fakultas Biologi Universitas Nasional; 2012.

5. Prasetyo D, Ancrenaz M, Morrogh-Bernard HC, Utami Atmoko S, Wich SA, van Schaik CP. Nest building in orangutans. Orangutans: Geographical Variation in Behavioral Ecology, Oxford University Press, Oxford. 2009:269-77.

6. Samson DR, Hunt KD. Chimpanzees preferentially select sleeping platform construction tree species with biomechanical properties that yield stable, firm, but compliant nests. PloS one. 2014;9(4):e95361.

7. van Casteren A, Sellers WI, Thorpe SK, Coward S, Crompton RH, Myatt JP, et al. Nest-building orangutans demonstrate engineering know-how to produce safe, comfortable beds. Proceedings of the National Academy of Sciences. 2012;109(18):6873-7.

8. Ancrenaz M, Gimenez O, Ambu L, Ancrenaz K, Andau P, Goossens B, et al. Aerial surveys give new estimates for orangutans in Sabah, Malaysia. PLoS Biology. 2004;3(1):e3.

9. Wich SA, Boyko RH. Which factors determine orangutan nests' detection probability along transects? Tropical Conservation Science. 2011;4(1):53-63. 
10. Mathewson P, Spehar S, Meijaard E, Sasmirul A, Marshall AJ. Evaluating orangutan census techniques using nest decay rates: Implications for population estimates. Ecological Applications. 2008;18(1):208-21.

11. Koh LP, Wich SA. Dawn of drone ecology: low-cost autonomous aerial vehicles for conservation. Tropical Conservation Science. 2012;5(2):121-32.

12. Ancrenaz M, Calaque R, Lackman-Ancrenaz I. Orangutan nesting behavior in disturbed forest of Sabah, Malaysia: Implications for nest census. International Journal of Primatology. 2004;25(5):9831000. doi: 10.1023/B:IJOP.0000043347.84757.9a.

13. Rayadin $Y$, Saitoh T. Individual variation in nest size and nest site features of the Bornean orangutans (Pongo pygmaeus). American Journal of Primatology. 2009;71(5):393-9.

14. Houle A, Chapman CA, Vickery WL. Tree climbing strategies for primate ecological studies. International Journal of Primatology. 2004;25(1):237-60.

15. van Casteren A, Sellers W, Thorpe S, Coward S, Crompton R, Ennos A. Why don't branches snap? The mechanics of bending failure in three temperate angiosperm trees. Trees. 2011;26(3):789-97. 16. Kindervater $\mathrm{KH}$. The emergence of lethal surveillance: Watching and killing in the history of drone technology. Security Dialogue. 2016;47(3):223-38.

17. Floreano D, Wood RJ. Science, technology and the future of small autonomous drones. Nature. 2015;521(7553):460-6.

18. Heatherly MC. Drones: The American controversy. Journal of Strategic Security. 2014;7(4):25.

19. Paneque-Gálvez J, McCall MK, Napoletano BM, Wich SA, Koh LP. Small drones for communitybased forest monitoring: An assessment of their feasibility and potential in tropical areas. Forests. 2014;5(6):1481-507.

20. Flynn KF, Chapra SC. Remote sensing of submerged aquatic vegetation in a shallow non-turbid river using an unmanned aerial vehicle. Remote Sensing. 2014;6(12):12815-36.

21. Sugardjito J. Selecting nest-sites of Sumatran organ-utans, Pongo pygmaeus abelii in the Gunung Leuser National Park, Indonesia. Primates. 1983;24(4):467-74.

22. Koops K, McGrew WC, de Vries H, Matsuzawa T. Nest-building by chimpanzees (Pan troglodytes verus) at Seringbara, Nimba Mountains: Antipredation, thermoregulation, and antivector hypotheses. International Journal of Primatology. 2012;33(2):356-80.

23. Mulyoutami E, Rismawan R, Joshi L. Knowledge and use of local plants from 'simpukng'or forest gardens among the Dayak community in East Kalimantan. IUFRO World Series Vol 21. 2008:121.

24. IUCN. The IUCN Red List of Threatened Species 2018 [cited 2017 13th December]. Available from: http://www.iucnredlist.org

25. Zahorka H. The Shamanic belian sentiu rituals of the Benuaq Ohookng, with special attention to the ritual use of plants. Borneo Research Bulletin. 2007;38:127-47.

26. Pereira JT, Sugau JB. A Guide to the Trees in Heritage Amenity Forest Reserve, Sandakan: Sabah Forestry Department; 2010.

27. Cheyne SM, Rowland D, Höing A, Husson SJ. How orang-utans choose where to sleep: Comparison of nest site variables. Asian Primates Journal. 2013;3:13-7.

28. Delgado RA, van Schaik CP. The behavioral ecology and conservation of the orangutan (Pongo pygmaeus): A tale of two islands. Evolutionary Anthropology: Issues, News, and Reviews. 2000;9(5):20118.

29. Rijksen HD. A fieldstudy on Sumatran Orang Utans (Pongo pygmaeus abelii Lesson 1827): Ecology, behaviour and conservation: Veenman; 1978. 


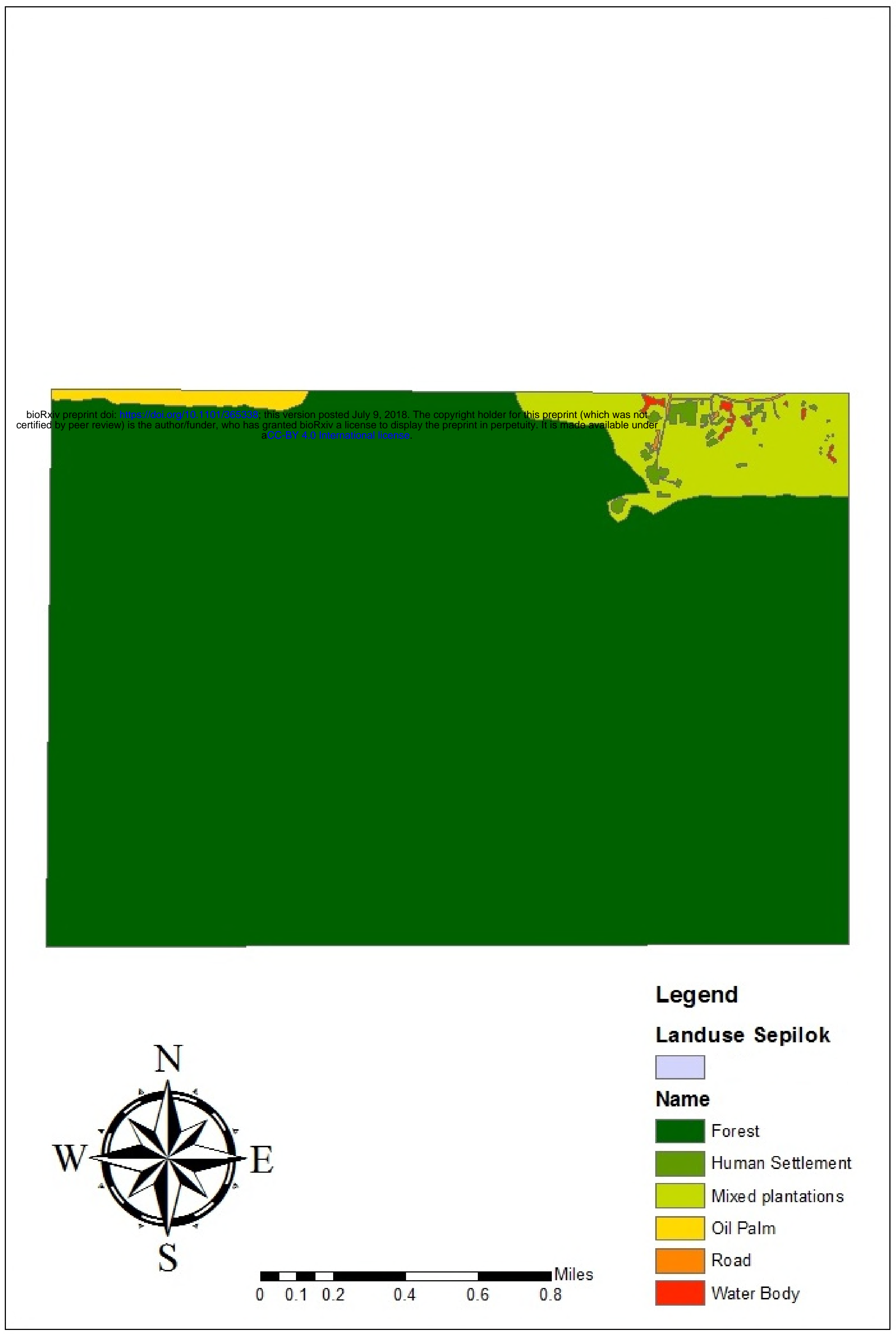




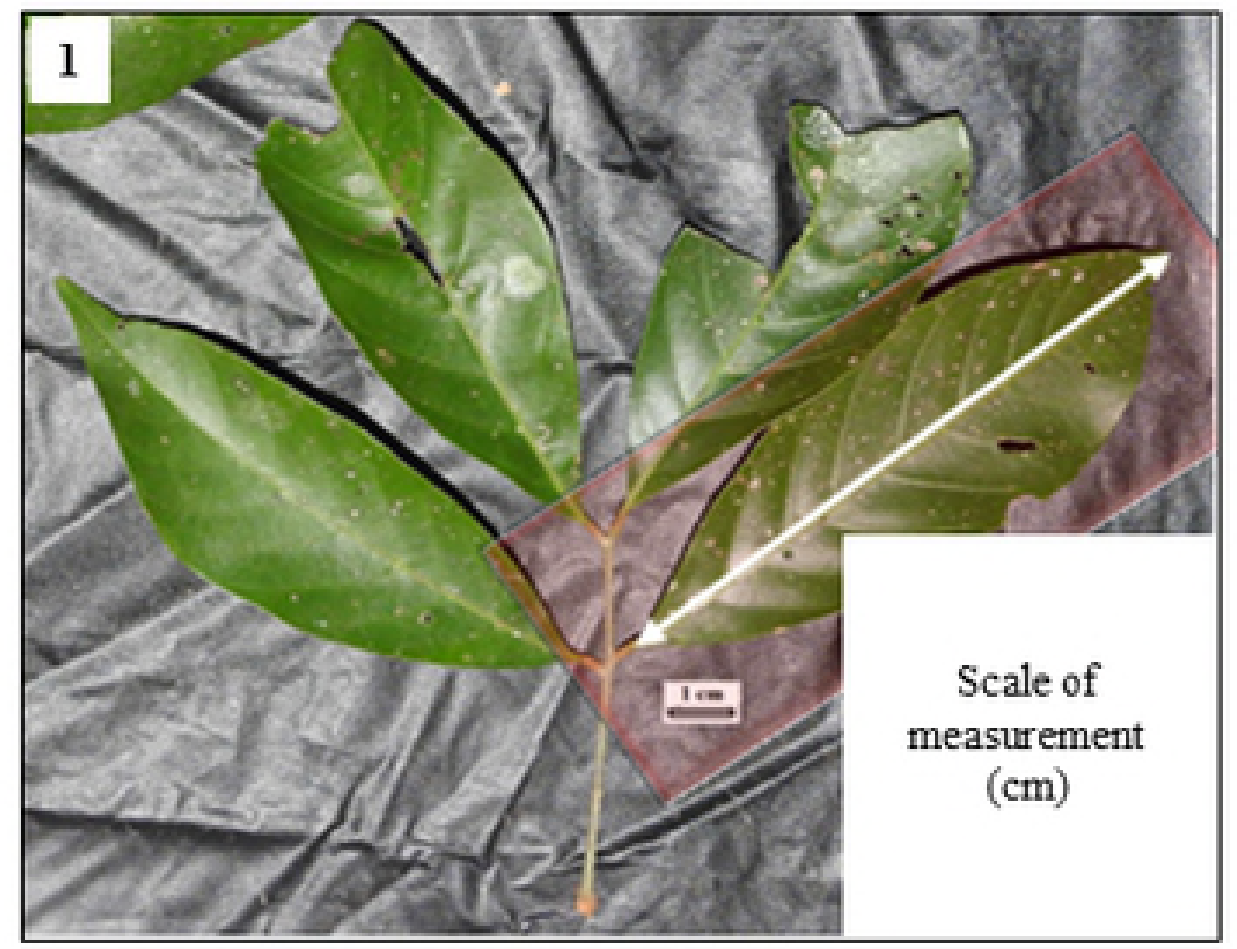

Fig 2 The mechanism of nest measurement using the Image J analysis was modified from van Casteren et al., (2012). 1. Leaf sample (red boxes) was measured and set as digital scale $(\mathrm{cm})$. 2.The length of nest was measure, the depth of the nest was taken from the centre of the nest. 3 . The nest width was measured perpendicular to the length arrow.
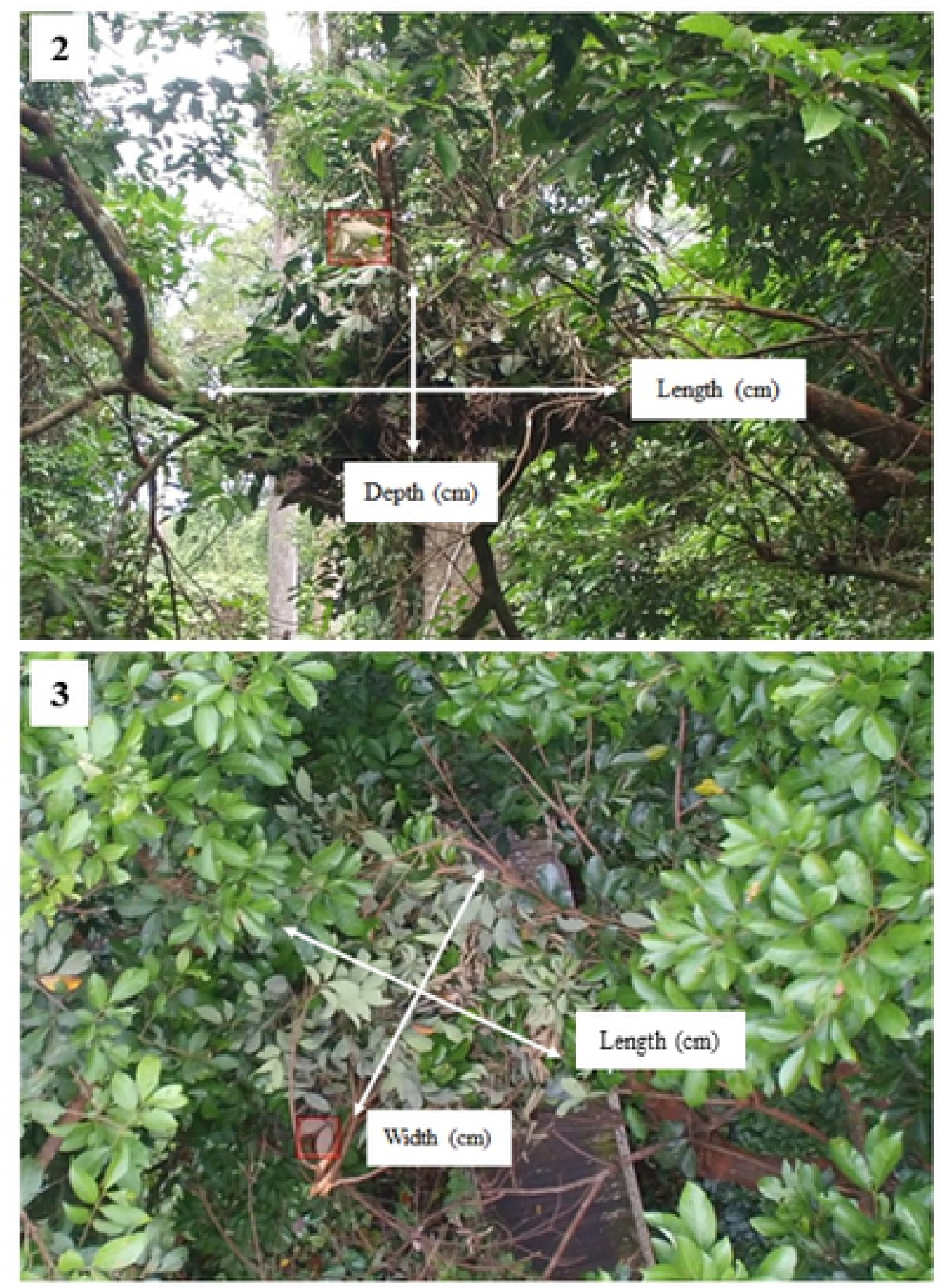


\section{a)}

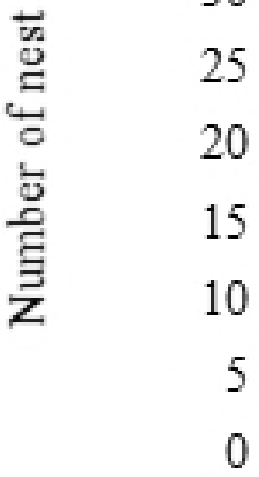

30

25

20

15

10

5

0
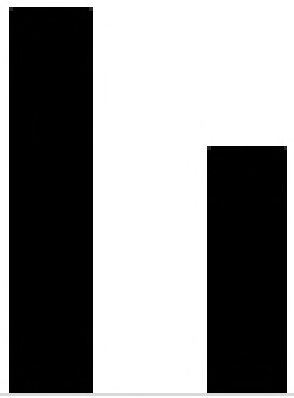

1

2

3

4

Nest position 
b)

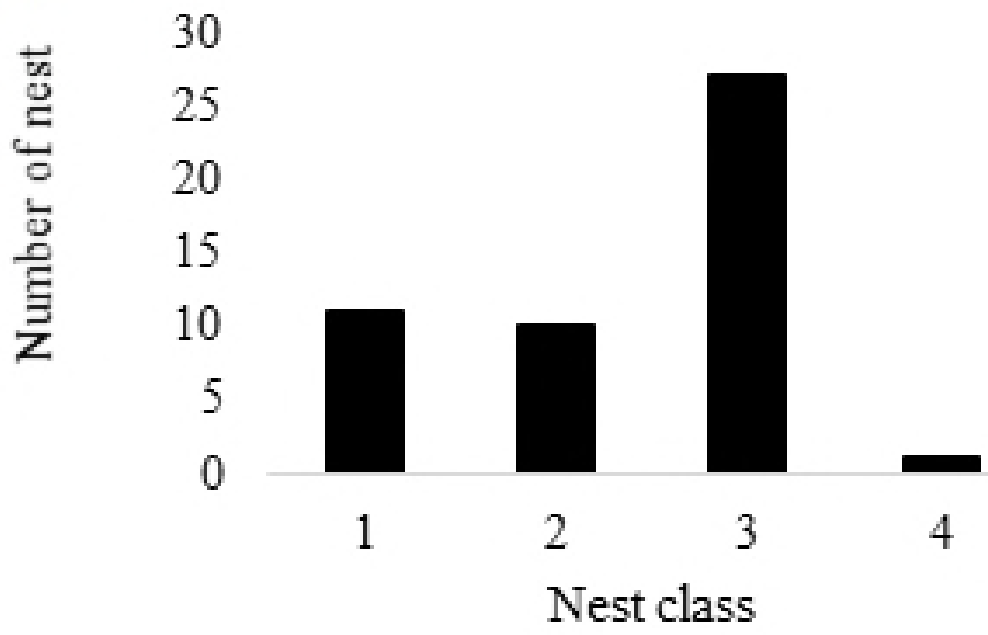




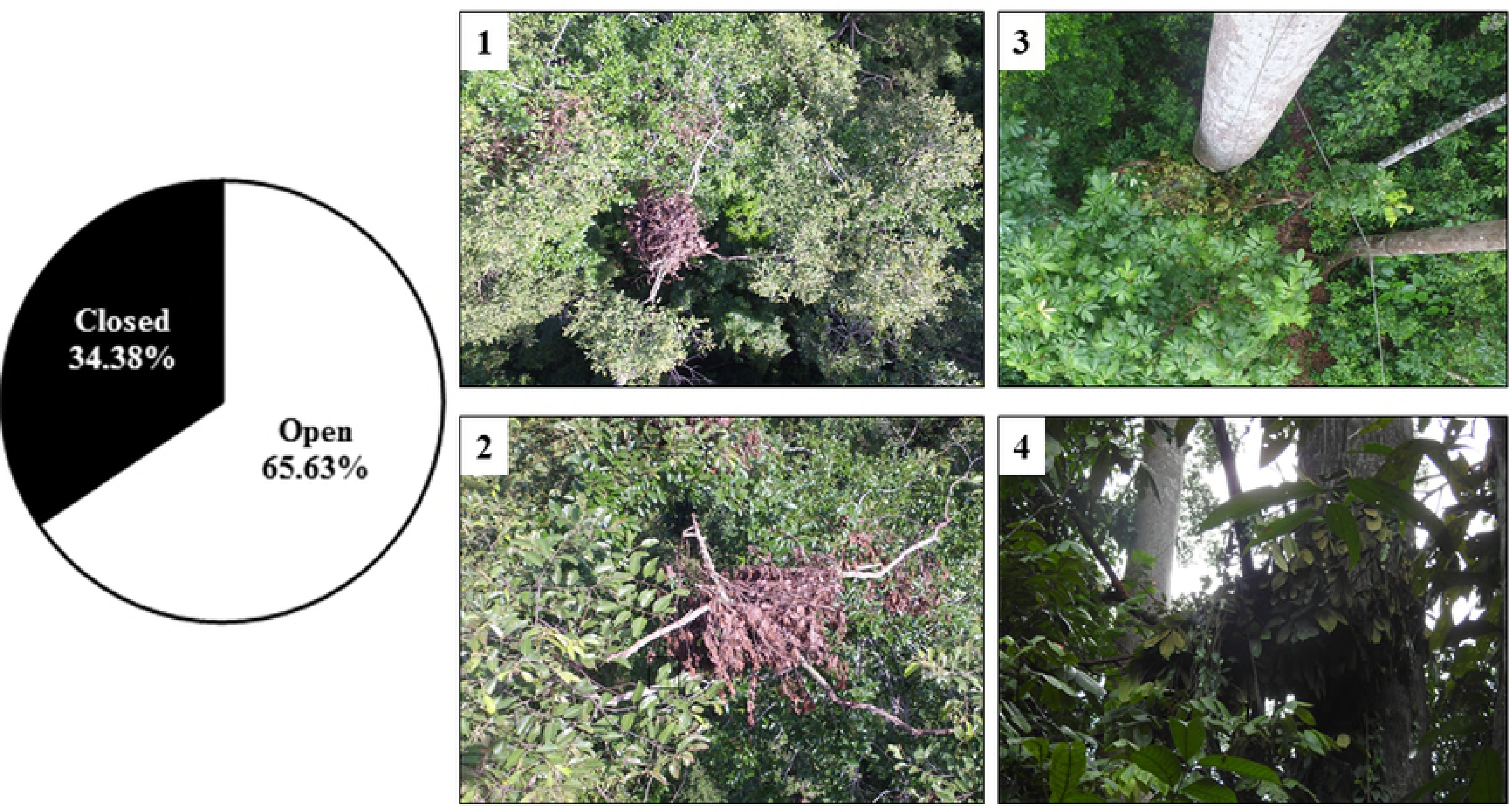




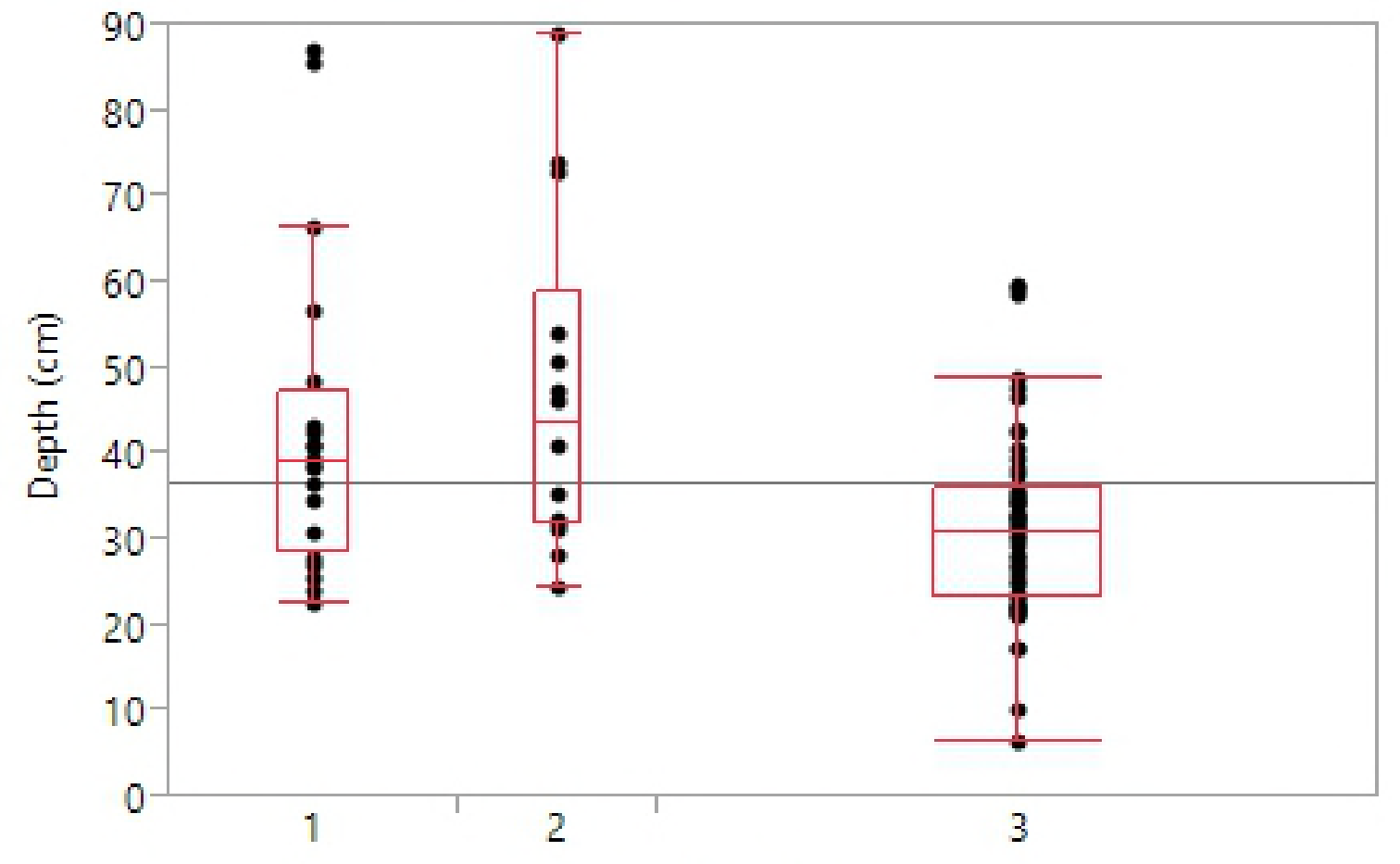

Nest class 


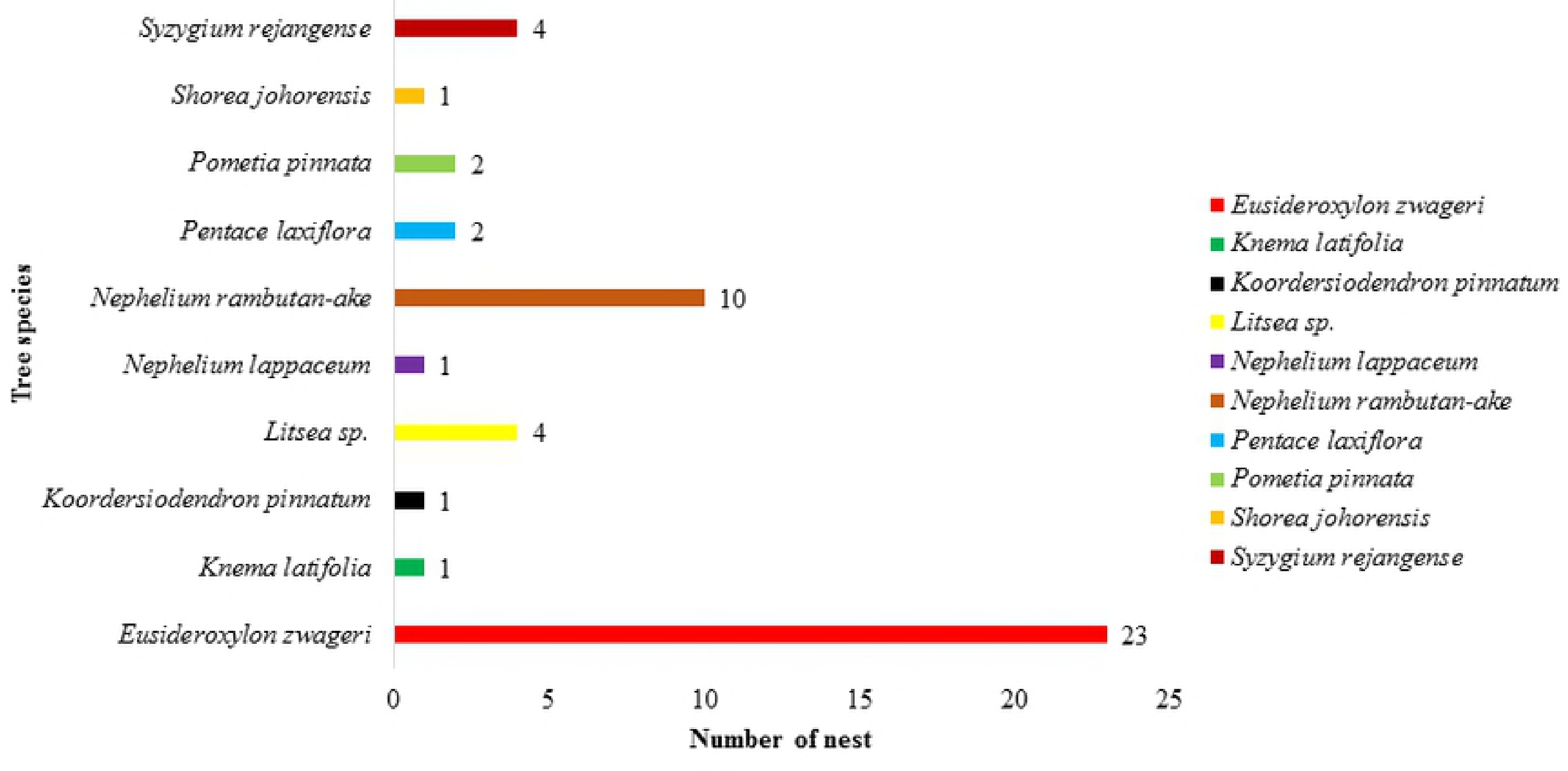

